\title{
Evaluation of the Efficacy Of $0.2 \%$ Chlorhexidine versus Herbal Oral Rinse on Plaque Induced Gingivitis- A Randomized Clinical Trail
}

\author{
Dr. Gautam Biswas ${ }^{[1]}$, Dr. Anup N. ${ }^{[2]}$, Dr Siddharth Acharya ${ }^{[3]}$, Dr. Himanshu \\ Kumawat ${ }^{[3]}$, Dr. Preeti Vishnani ${ }^{[3]}$, Dr. Swasti Tambi ${ }^{[3]}$. \\ 1. Senior Lecturer, Dept of Public Health Dentistry, Jaipur Dental College \\ 2. Professor \& Head, Dept of Public Health Dentistry Jaipur Dental College \\ 3. Post Graduate Student, Dept of Public Health Dentistry Jaipur Dental College
}

\begin{abstract}
Background: Supragingival plaque control is fundamental to the prevention and management of periodontal diseases. However significant proportions of all individuals fail to practice a high standard of plaque removal. The adjunctive use of chemicals would, therefore appear a way of overcoming deficiencies in mechanical tooth cleaning habits. This prospective, randomized positively controlled clinical trial was designed to evaluate the short-term clinical effects of a Herbal mouthwash in the reduction of plaque and gingival inflammation in subjects with gingivitis.

Methods: Fifty subjects, 20 to 40 years of age diagnosed with chronic generalized gingivitis were selected and randomly divided into two groups: Group 1 - Chlorhexidine mouthwash, Group 2 - Herbal mouthwash. Clinical evaluation was undertaken using the gingival index, the plaque index and bleeding on probing at baseline, 1 weeks, 2 weeks and 4 weeks.

Results: Both chlorhexidine and herbal mouthwash showed a significant reduction in Plaque and gingival index scores from baseline to 1st week, 2nd week and at 4th week. However, the improvement in plaque and gingival index scores were better in chlorhexidine group than herbal mouthwash. Both mouthwashes were found to be equally effective in reducing bleeding on probing.

Conclusions: Unlike chlorhexidine mouthwash, herbal mouthwash was not associated with any discoloration of teeth or unpleasant taste and was effective in reducing plaque accumulation and gingival inflammation. However, Chlorhexidine still remains a gold standard in reducing plaque, gingivitis and bleeding on probing.

Keywords: chlorhexidine, herbal mouthwash, gingivitis, antiplaque agent.
\end{abstract}

\section{Introduction}

Periodontal diseases are among the most common infectious diseases affecting human kind and can lead to destruction of the periodontal ligament, cementum, gingiva and alveolar bone. Plaque is the primary etiological factor in gingival inflammation ${ }^{1}$. Thus, control of dental plaque holds the key to halt the progression of periodontal disease. Since a majority of population is not able to perform plaque control effectively, the onus lies on the dental health care provider to impart the correct knowledge about the oral hygiene aids and adjunctive use of various chemical plaque control agents. Chemotherapeutic mouthrinses provide chemically significant benefit in the reduction of plaque induced gingivitis. Mouthrinses have the ability to deliver therapeutic ingredients and benefits to all accessible surfaces in the mouth including interproximal surfaces. They also remain effective for extended period of time depending on their substantivity. Chlorhexidine has been prescribed by dentists for decades and accepted as the gold standard in reducing dental plaque as it has profound antiplaque and antibacterial properties ${ }^{2,3,4}$. However, it has few undesirable side effects primarily brown staining of the teeth ${ }^{5}$ and transient impairment of taste sensation.

Recently, numerous studies have been conducted to verify the enormous wealth of medicinal plants. These herbal mouthwashes are gaining popularity as they contain naturally occurring ingredients called as Phytochemicals that achieve the desired antimicrobial and anti-inflammatory effects. Herbal formulations may be more appealing because they work without alcohol, artificial preservatives, flavors or colors. One of the recently marketed herbal mouthwash is Herboral (by M-Tech Innovation Private ltd., Pune, India). This herbal mouthrinse contains numerous herbs with significant anti-inflammatory properties. The principal ingredients are:-

1. Azadirachta indica (neem ) - It contains limonoids (triterpenoids) which have antimicrobial effects. It also has anti-inflammatory property because of the presence of flavonoids. Quercetin is a bioflavonoid with an antioxidant potential comparable to that of vitamin $\mathrm{E}$. The aqueous extract of neem bark and leaf possesses anti- 
complement and immunostimulant activity. Neem oil is known to selectively activate the cell-mediated immune mechanisms to elicit an enhanced response to subsequent mitogenic or antigenic challenge. ${ }^{6,7}$

2. Caryophyllus aromaticus (clove) -Eugenol, the primary component of clove's volatile oils, functions as an anti-inflammatory substance. It has beta-caryophyllene, which is a mild anaesthetic as well as an anti-bacterial agent $^{8}$. Clove also contains a variety of flavonoids, including kaempferol and rhamnetin, which also contribute to clove's anti-inflammatory and antioxidant properties. It also has antiseptic property. ${ }_{9,10}$

3. Threemyrobalas (triphala) -Triphala is a combination of ripe, healthy and dried fruits in equal quantities of Amalaki (Emblica officinalis), Haritaki (Terminalia chebula) and Vibhitaki (Terminalia belerica). It possesses antibacterial, antiseptic and anti-inflammatory property. The biopotency of triphala is mainly due to the presence of gallic acid and tannins. Tannins act as antioxidant and improve blood circulation. The antioxidant action is by inhibition of free radical formation and acting as a scavenger for free radicals. ${ }^{11}$

4. Ocimum sanctum (tulsi) - It is the Queen of Herbs" - the most sacred herb of India. It contains alkaloids, glycosides, tannins and volatile oil (eugenol, thymol, Urosolic acid). Tannins act as an antioxidant and scavenger against reactive oxygen species and free radicals. Urosolic acid helps in increasing leukocyte count and significantly protects mast cell membrane; thus, preventing cell degradation and histamine release. Linolenic acid present in O.sanctum has the capacity to block both the cyclo-oxygenase and lipoxygenase pathways of arachidonate metabolism and hence responsible for its anti inflammatory activity ${ }^{10,12,13}$.

5. Apium Graveolen (celery) - It contains flavonoids called phthalides, shown to have anticancer, antiinflammatory and teeth whitening properties. It also contains vitamin A, C and B-complex known to promote good oral and general health.

6. Glycyrrhiza Glabra (Licorice) - The key therapeutic compound in licorice is glycyrrhizin. It prevents the breakdown of adrenal hormones such as cortisol (the body's primary stress-fighting adrenal hormone), making these hormones more available to the body, hence acting as immunostimulant. Licorice flavonoid constituents mainly include flavones, isoflavones and chalcones which show antioxidant, anti-inflammatory and antibacterial properties $^{14}$.

7. Quercus infectora (oak tree) - It has profound antibacterial activity. Due to its action on antioxidant enzyme, it is efficacious in wound healing. ${ }^{15}$

8. Mimusops elengi (bakula) - It has several triterpenoids, steroids, flavonoids and alkaloids. Among these polyphenolic compounds like flavonoids imparts the antioxidant properties, thus offering protection from free radicals. Pentahydroxyflavanoids offer antibacterial properties. Also, it contains tannins with strong astringent property. $^{16}$

9. Acacia Catechu (katha) - Its chief ingredients are catechin, taxifolin, flavonoid and catechutannic acid. Catechin has strong astringent and hemostatic properties and prevents free radical oxidative damage to cells. Taxifolin has anti-inflammatory, antibacterial and antioxidant property and flavonoids has anti-inflammatory properties. $^{17}$

10.Mentha spicata (spear mint) - It has astringent and anti-inflammatory activity which is due to presence of ursane and glycosides. ${ }^{18}$

Thus, the present study was undertaken to compare the clinical efficacy of $0.2 \%$ chlorhexidine with herbal mouthwash on gingival health status over a period of 4 weeks.

\section{Materials And Method}

This study was designed and conducted in the Department of Public Health Dentistry at Jaipur Dental College, Jaipur, India. 50 patients with clinical signs and symptoms of chronic plaque induced gingivitis were selected from the dental OPD. All patients were systemically healthy and between 20 to 40 years of age. Pregnant or lactating females were not included in the study. Approval from the Institutional Ethics Committee of Jaipur Dental College, Jaipur was obtained before initiating the study. An informed consent was obtained from all the participants. After screening and baseline measurements, all subjects received a complete oral prophylaxis.

The subjects were randomly assigned to one of the 2 treatment groups i.e. $0.2 \%$ chlorhexidine (HEXIDINE by ICPA Health products ltd.) and Herbal mouthwash (HERBORAL) and were followed for a period of 4 weeks.

In the majority of cases, participants were examined at the same time of day to reduce extraneous variables in plaque accumulation, such as the length of time between home care and data collection.

25 Subjects (10 males and 15 females) subjects were instructed to use $10 \mathrm{ml}$ of $0.2 \%$ chlorhexidine mouthwash twice daily and 25 subjects ( 8 males and 17 females) Subjects were instructed to use $10 \mathrm{ml}$ of herbal mouthwash twice daily. Individuals were given the same type of toothbrush (by Oral B) and toothpaste (Pepsodent) and were also given appropriate oral hygiene instructions.

Data was collected at baseline, 1 week, 2 week and 4th week utilizing the:-

a. Plaque index ${ }^{19}$ 
b. Gingival index ${ }^{20}$

c. Bleeding on probing (percentage of bleeding sites)

\section{Statistical Analysis}

Statistical analysis was carried out by means of Minitab version 14. Paired comparison tests were used to confirm the results with $\mathrm{p}$ value set at $<0.05$. Mean and standard deviation was calculated using the paired $\mathrm{t}$ test and mean difference was calculated at each week to yield significant results.

\section{Results}

Fifty participants (32 females and 18 males) participated in the study and the response rate to the study was $100 \%$.

\section{GINGIVAL HEALTH}

Analysis of plaque indices showed that both chlorhexidine and herbal mouthwash were helpful in reducing mean plaque accumulation from baseline to 4 weeks. The mean Plaque index scores reduced from $3.8 \pm$ 0.7 to $1.24 \pm 0.92$ in chlorhexidine group and from $3.88 \pm 0.83$ to $2.28 \pm 0.93$ in the herbal group. (Fig 1)

Fig. 1 -Reduction in Plaque index with chlorhexidine and herbal mouthwash from baseline to 4 weeks

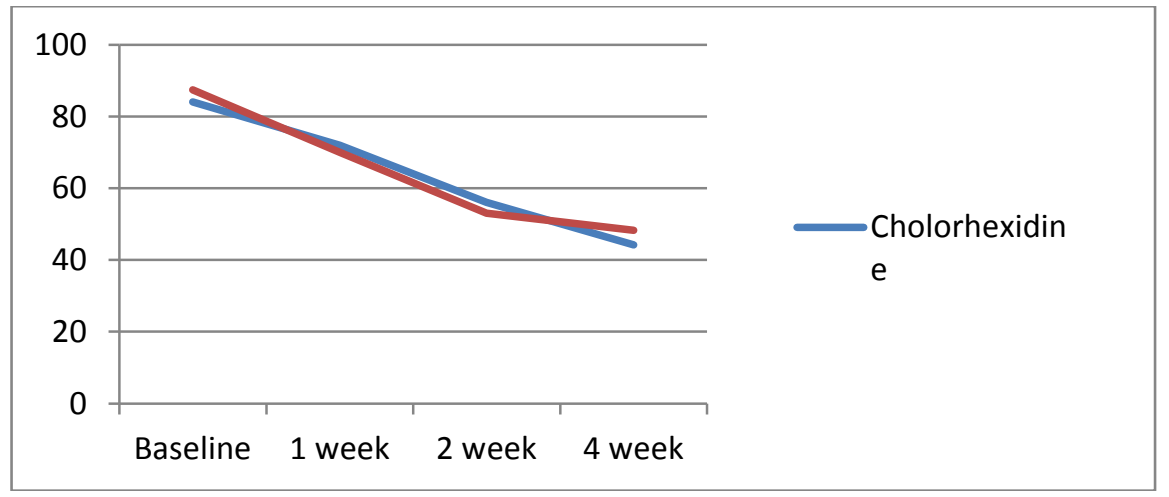

Analysis of gingival scores indicated that chlorhexidine and herbal mouthwash individually showed a statistically significant improvement from baseline to 1 st week with further improvement at 2nd week and 4th week. The reduction in Gingival index scores in Chlorhexidine and herbal mouthwash group was $2.0 \pm 0.00$ to $0.28 \pm 0.45$ and $1.96 \pm 0.20$ to $0.6 \pm 0.5$ (from baseline to 4 weeks) respectively. (Fig 2)

Fig 2 - Reduction in Gingival index with chlorhexidine and herbal mouthwash from baseline to 4 weeks

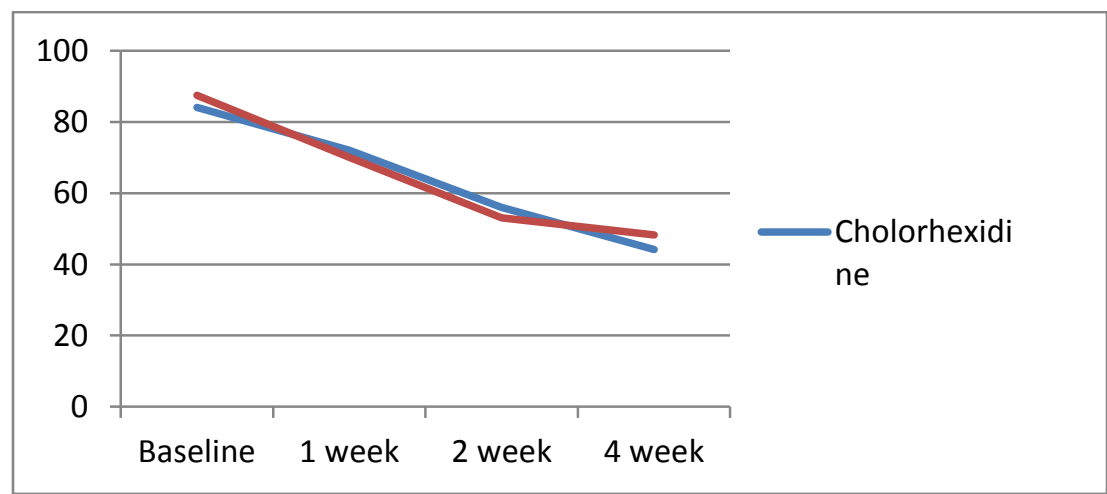

Intergroup comparisons depicted that chlorhexidine was significantly more potent in reduction of plaque accumulation and gingivitis as compared to herbal mouthwash, signifying that chlorhexidine still remains a gold standard. 


\section{BLEEDING ON PROBING}

Although results do not reach to level of significance when intergroup comparisons were made but individually both chlorhexidine and herbal mouthwash were effective in reducing bleeding sites. The mean percentage of bleeding sites reduced from $84.0 \pm 37.2 \%$ to $44.2 \pm 50.3 \%$ in chlorhexidine group and $87.4 \pm$ $48.23 \%$ to $56.1 \pm 33.5 \%$ in herbal mouthwash group at 4 weeks. Herbal mouthwash contains certain ingredients with astringent property, so a steady fall in bleeding sites was noticed as compared to chlorhexidine. (Fig 3)

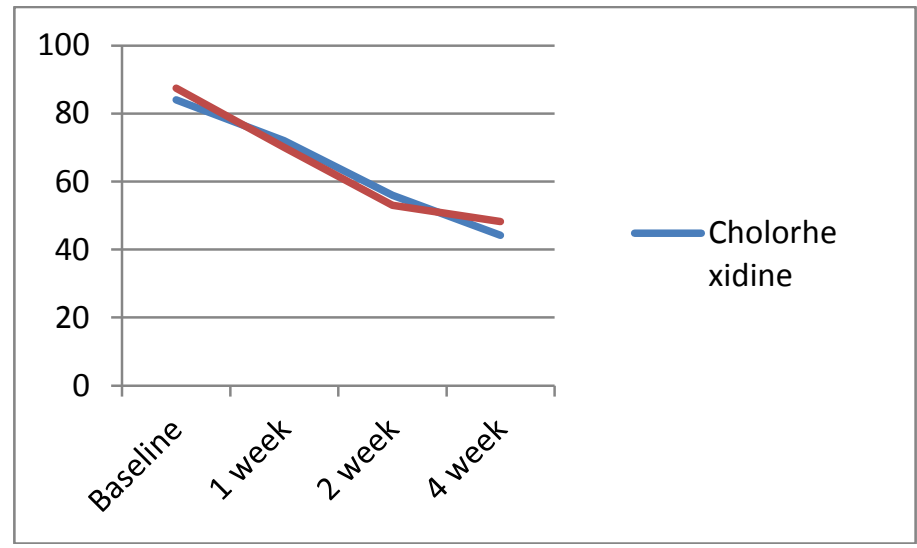

Fig 3 - Reduction in percentage of Bleeding sites with chlorhexidine and herbal mouthwash from baseline to 4 weeks

\section{Discussion}

The study was conducted to determine the efficacy of herbal mouthwash verses chlorhexidine mouthwash on gingival status and plaque biofilm accumulations over a period of four weeks.

Chlorhexidine remains the gold standard antiplaque and antigingivitis agents. Its effectiveness can be attributed to it bactericidal and bacteriostatic effects and its substantivity within the oral cavity. Numerous studies have reported the efficacy of chlorhexidine in reducing plaque accumulation and gingival inflammation ${ }^{21,22}$.

Azadirachta indica has been shown to be efficient in reducing the plaque index and bacterial count ${ }^{23}$. In a comparative study between Azadirachta indica and chlorhexidine, it was demonstrated that A. indica-based mouth rinse was highly efficacious in reducing plaque index, gingival index and gingival bleeding index and that it may be used as an alternative therapy in the treatment of periodontal disease ${ }^{24}$. Neem extract has also shown to effectively reduce IL-2 and Interferon- gamma levels in gingival tissue of patients with chronic gingivitis ${ }^{25}$.

Methanolic extract of Quercus has shown to have a significant antibacterial activity against Streptococcus mutans, Streptococcus salivarius and Lactobacillus which play a major role in plaque formation and its activity against caries and gingivitis ${ }^{26}$. Bajaj et al stated that $0.6 \%$ Triphala has an inhibitory effect on plaque, gingivitis and growth of Streptococcus mutans and Lactobacillus and was found to be equally effective as $0.1 \%$ Chlorhexidine ${ }^{27}$. Similar results were reported by Gupta et al wherein $0.6 \%$ Triphala was found to be highly effective in preventing plaque accumulation and gingivitis ${ }^{28}$.

Tulsi extract has also shown to demonstrate a significant antimicrobial potential against streptococcus mutans $^{29}$. Goultschin et al tested the effect of Glycyrrhizin, the main saponin of licorice on gingival health as a supplemental agent in toothpaste. The toothpaste, however failed to show any significant reduction in plaque, gingival and bleeding indices ${ }^{30}$. A study by Jayashankaret al also demonstrated that a herbal toothpaste containing Mimusopselengi, Syzgium aromaticum and Quercus infectoria significantly reduced Plaque index and bleeding on probing ${ }^{31}$.

A study by Pistorius showed that subgingival irrigation with an herbal- based mouthrinse (containing salvia officinalis, metha piperita, menthol, matricaria chaxaomilla, commiphora myrrha, carvum carvi, Eugenia caryophyllus and Echinacea purpurae) proved to be fruitful in reducing gingival inflammation as it leads to significant reduction in both bleeding and gingival score ${ }^{32}$.

In the present study, analysis of plaque index suggest that both the mouthwashes were helpful in reducing plaque but chlorhexidine reduced plaque scores to greater extent as compared to herbal mouthwash group. These findings are similar to previous studies ${ }^{33,34}$. The reduction in plaque score in chlorhexidine group was due to antibacterial action. In a microbiological study ${ }^{34}$ it was reported that herbal mouthwash had less potent antibacterial action than chlorhexidine. Chlorhexidine has antibacterial activity against actinomyces species, periodontal pathogens Eubacterium nodatum, Tanerella forsythia and Prevotella species, as well as the cariogenic pathogen Streptococcus mutans. However, variations in the plaque accumulation may also have been 
influenced by the Hawthorne effect or the tendency of participants to improve behavior because of the expectation created by the situation.

Chlorhexidine was also more efficient in improving gingival inflammation. Both chlorhexidine and herbal mouthwash were found to be helpful in reducing bleeding score but results were not significant statistically. This substantial reduction in bleeding score in herbal group might be because of its ingredients Mimusopselengi, Acacia catechu and Mentha spicata which reduce bleeding because of their astringent action. These results are consistent with other findings by Scherer et al 1998 who demonstrated that herbal mouthwash reduces gingival bleeding over a period of time ${ }^{35}$.

The results of the present study indicate that both mouthwashes were effective in improvement of plaque and gingivitis scores, though Chlorhexidine showed better clinical improvement. Herbal mouthwash was found to be comparable to Chlorhexidine in reducing bleeding on probing.

Thus, herbal mouthwash can be effectively used as an alternative to Chlorhexidine and can be prescribed for longer duration without any side effects for management of periodontal diseases.

\section{Conclusion}

Herbal products have shown promising results with minimal side effects. Also, their additional effect on inflammatory pathways and antioxidant potential, make them eligible to be used as effective antigingivitis agents. These herbal ingredients are abundantly available, easily accessible, economically feasible and culturally acceptable. They possess minimal side effects and hence can be recommended for long term use. Though around 6000 plants in India are used as herbal medicine, little research has been conducted to evaluate the efficacy, safety and properties of herbal products. Hence, more clinical trials are required to know the effectiveness of natural products and their advantage over the prototype chemical plaque control agents.

\section{Acknowledgement}

I want to acknowledge all the participants of the study who voluntarily participated in our study group. I want to thank our institution for constant support.

\section{References}

[1]. Loe H, Theilade E, Jensen SB. Experimental gingivitis in man. J Periodontol. 1965; 36:177-87.

[2]. Loe H, Schiott C, Karring G, Karring T. Two years oral use of chlorhexidine in man. I. General design and clinical effects. J Periodont Res. 1976; 11: 135-44

[3]. Segreto VA, Collins EM, Beiswanger BB, De La Rosa M, Isaacs RL, Lang NP, Mallatt ME and Meckel AH. A comparison of mouthrinses containing two concentration of chlorhexidine. J Periodont Res. 1986; 21 (Suppl 16):23-32

[4]. Grossman E, Reiter G, Sturzenberger OP, et al. Six month study on the effects of a chlorhexidine mouth rinse on gingivitis in adults. J Periodontal Res. 1987; 58: 827.

[5]. Lang NP, Hotz P, Graf H, et al. Effects of supervised Chlorhexidene mouthrinses in children: a longitudinal clinical trial. J Periodontal Res. 1982; 17: 101 .

[6]. Manikandan P, Anandan R, Nagini S. Evaluation of Azadirachta indica leaf fractions for in vitro antioxidant potential and protective effects against H2O2-induced oxidative damage to pBR322 DNA and red blood cells. J Agric Food Chem. 2009 ;57(15):6990-6.

[7]. Biswas K, Chattopadhyay I, Banerjee RK, Bandyopadhyay U. Biological activities and medicinal properties of neem (Azadirachta indica). Current Science. 2002; 82(11):1336-1345.

[8]. Lining C, Christine DW. Compounds from Syzygium aromaticum possessing growth inhibitory activity against oral pathogens. Journal of Natural Products. 1996; 59: 987-90.

[9]. Nassar MI, Gaara AH, El-Ghorab A, Farrag AH, Shen H, Huq E, Mabry TJ. Chemical Constituents of Clove (Syzygium aromaticum, Fam.Myrtaceae) and their antioxidant Activity. Rev. Latinoamer. Quim.. 2007; 35: 47-57.

[10]. Joshi B, Sah GP, Basnet B, Bhatt MR, Sharma D, Subedi K, Pandey J, Malla R. Phytochemical extraction and antimicrobial properties of different medicinal plants; Ocimum sanctum (Tulsi), Eugenia caryophyllata (Clove), Achyranthes bidentata (Datiwan) and Azadirachta indica(Neem). Journal of Microbiology andAntimicrobials. 2011; 3(1):1-7.

[11]. Biradar YS, Dhalwal K, Shinde V, Khandelwal KR, Rajani M. Comparative phytochemical analysis and antioxidant activity of Triphala mashi and Triphala. Nig J Nat Prod and Med. 2006;10:73-76.

[12]. Singh S. Comparative evaluation of anti-inflammatory potential of fixed oil of different species of Ocimum and its possible mechanism of action. Indian J Exp Biol. 1998; 36:1028-31.

[13]. Singh S. Comparative evaluation of anti-inflammatory potential of fixed oil of different species of Ocimum and its possible mechanism of action. Indian J Exp Biol. 1998; 36(10): 1028-1031.

[14]. Zhang Q, Ye M. Chemical analysis of the Chinese herbal medicine Gan-Cao (licorice). Journal of Chromatography. 2009; 1216: 1954-1969.

[15]. Umachigia SP, Jayaveerab KN, Ashok Kumar CK, Kumard GS, Vrushabendraswamye BR, Kumar DV Studies on Wound Healing Properties of Quercus infectoria. Tropical Journal of Pharmaceutical Research. 2008; 7 (1): 913-919.

[16]. Saha MR, Hasana SMR, Akter R, Hossaina MM, Alam MS, Alam MA, Mazumder MEH. In vitro free radical scavenging activity of methanol extract of the leaves of mimusops elengi linn. Bangl. J. Vet. Med. (2008). 6 (2): 197-202.

[17]. Lakshmi.T, Roy A, Geetha RV .Acacia Catechu Willd -A Gift From Ayurveda To Mankind -A Review. T Ph Res. 2011; 5(2): 273293.

[18]. Zheng J, Wu LJ, Zheng L, Wu B, Song AH. Two new monoterpenoid glycosides from Mentha Spicata L. J Asian Nat Prod Res. 2003; 5(1): 69-73.

[19]. Turskey S, Gilmore ND, Glickman I. Reduced plaque formation by the chlormethyl analogue of Vit. C. J Periodontol. $1970 ; 41(1): 41-3$ 
[20]. Loe H., Silness J. Periodontal disease in pregnancy. Acta Odontol Scand. 1963; 21:533-51.

[21]. Becerik, S., Turkodlu, O., Emingil, G., Vural, C., Ozdemir, G., Atilla, G Antimicrobial effect of adjunctive use of chlorhexidine mouthrinse in untreated gingivitis: a randomized, placebo- controlled study. APMIS. 2011; 119: 364-372.

[22]. Corbet EF, Tam JO, Zee KY, Wong MC, Lo EC, Mombelli AW, Lang NP. Therapeutic effects of supervised chlorhexidine mouthrinses on untreated gingivitis. Oral Dis. 1997 ;3 (1):9-18.

[23]. Pai M.R, Acharya L.D, Udupa N. Evaluation of antiplaque activity of Azadirachta indica leaf extract gel- A 6-week clinical study. Journal of Ethnopharmacol. 2004; 90(1): 99-103

[24]. Botelho MA, Santos RA, Martins JG, Carvalho CO, Paz MC, Azenha C, Ruela RS, Queiroz DB, Ruela WS, Marinho G Ruela FI. Efficacy of a mouthrinse based on leaves of the neem tree (Azadirachta indica) in the treatment of patients with chronic gingivitis: A double-blind, randomized, controlled trial. Journal of Medicinal Plants Research.2008; 2 (11):341-346.

[25]. Sharma S, Saimbi CS, Koirala B, Shukla R. Effect of various mouthwashes on the levels of IL-2and Interferon - gamma in chronic gingivitis. J Clin Pediatr Dent. 2008; 32(2): 111-114.

[26]. Vermani A, Navneet, Prabhat. Screening of Quercus infectoria gall extracts as anti-bacterial agents against dental pathogens. Indian J Dent Res. 2009; 20(3): 337-9.

[27]. Bajaj N, Tandon S. The effect of Triphala and Chlorhexidine mouthwash on dental plaque, gingival inflammation and microbial growth. Int J Ayurveda Res. 2011;2(1): 29-36.

[28]. Gupta K, Tandon S, Rao S, Malagi KJ. Effects of triphala mouthwash on the oral health status. Malays Dent J. 2004; $25: 27-46$.

[29]. Agarwal P, Nagesh L, Muralikrishnan. Evaluation of various concentrations of Tulsi (Ocimum Sanctum) extract against Streptococcus mutans : an in vitro study. Indian J Dent Res. 2010; 21: 357-359.

[30]. Goultschin J, Palmon S, Shapira L, Braver L, Gedelia I. Effect of glycyrrhizin containing toothpaste on dental plaque reduction and gingival health in humans- A pilot study. J Clin Periodontol. 1991; 18(3): 210-212.

[31]. Jayashankar S, Panagoda GJ, Amaratunga EAPD, Perera K, Rajapakse PS. A randomised double blind placebo controlled study on the effects of a herbal toothpaste on gingival bleeding, oral hygiene and microbial variables. Ceylon Med J.2011; 56: 5-9.

[32]. Pistorius A. Efficacy of Subgingival Irrigation Using Herbal Extracts on Gingival Inflammation. J Periodontol. 2003; 74(5): 616622

[33]. Overholser CD, Miller TF, DePaola LG, Minah GE, Niehaus C. Comparative effects of 2 chemotherapeutic mouthrinses on the development of supragingival dental plaque and gingivitis. J Clin Periodontol. 1990; 17: 575-579.

[34]. Haffajee AD, Yaskell T and Socransky SS. Antimicrobial Effectiveness of an Herbal Mouthrinse Compared With an Essential Oil and a Chlorhexidine Mouthrinse. J Am Dent Assoc. 2008; 139(5): 606-611.

[35]. Scherer W, Gultz J, Lee SS, Kaim J. The ability of an herbal mouthrinse to reduce gingival bleeding. J Clin Dent. 1998; 9(4): 97100 . 